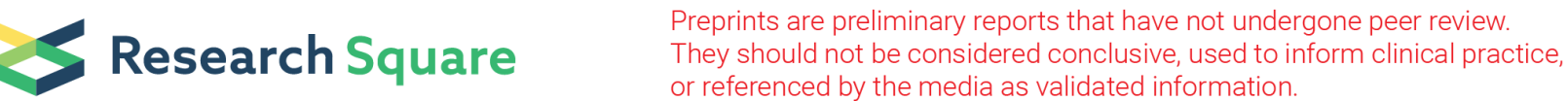

\section{Insights Into the Proteomic Profile of Newly Harvested Corn and Metagenomic Analysis of the Broiler Intestinal Microbiota}

Dafei Yin

Shenyang Agricultural University

\section{Youli Wang}

China Agricultural University

\section{Liqun Wang}

China Agricultural University

\section{Yuqin Wu}

China Agricultural University

\section{Xiaoyi Bian}

China Agricultural University

\section{Samuel E. Aggrey}

University of Georgia

Jianmin Yuan ( $\nabla$ yuanjm@cau.edu.cn )

China Agricultural University https://orcid.org/0000-0002-0169-3799

\section{Research}

Keywords: corn, proteome, metagenome, storage, broilers

Posted Date: July 15th, 2021

DOl: https://doi.org/10.21203/rs.3.rs-687305/v1

License: (c) (i) This work is licensed under a Creative Commons Attribution 4.0 International License.

Read Full License

Version of Record: A version of this preprint was published at Journal of Animal Science and Biotechnology on February 9th, 2022. See the published version at https://doi.org/10.1186/s40104-02100656-1. 


\section{Abstract}

\section{Background}

The use of newly harvested corn in feed causes wet droppings in broilers and increased feed cost which was termed as "new season grain problem". The present study was conducted to evaluate the proteomic profile of newly harvested corn and the subsequent influence on intestinal microbiol community for broiler chickens.

\section{Methods}

Newly harvested corn stored for either half a month (HM) or two months (TM) was used, and the pasting properties, total soluble sugars, and proteomic analysis technology was used to explore the influence of storage on natural aging corn properties. Additionally, seventy-two 7d Ross 308 male broiler chicken were fed with different stored corn. Apparent metabolizable energy (AME), digesta viscosity, intestinal morphology and microbiota were examined to explore the influence of feed corn storage on broiler chickens.

Results

Pasting properties in the TM corn exhibited decreased viscoelastic properties. Proteomic studies found a total of 26 proteins that were differentially expressed between the two treatment groups. Proteins involved in starch and polysaccharides biosynthesis were upregulated in TM compared with HM. Chickens fed on TM diet had higher relative energy utilization compared to the HM birds. With increased corn storage, the relative digesta viscosity decreased significantly $(P \leq 0.05)$. The total number of goblet cells and lymphocytes was lower in chickens fed the TM diet. The microbiota data showed that the TM chickens had decreased abundance of diarrheal bacteria such as Hungatella hathewayi and Bacteroides fragilis, and increased butyrate-producing bacteria such as Alistipes compared to the HM chickens.

\section{Conclusions}

Storage of newly harvested corn induced the synthetic reaction of large molecules and changed the solubility of starch and protein with increasing soluble sugars and decreasing pasting properties that may improve the fermentation of intestinal microbiota, improve the energy utilization and protect gut health without the risk of diarrhea.

\section{Introduction}

Corn is the most abundantly grown cereal grain and has high nutritional value, especially for poultry and swine. As corn production is seasonal, corn grains need to be stored throughout the year to provide sufficient supplies for feed industries. However, there is an asynchrony of supply and demand that leads to a large number of newly harvested corn being processed as animal feed during each harvest season. The use of newly harvested corn in poultry diets is especially problematic because it decreases the 
apparent metabolizable energy (AME) and feed conversion ratio and causes wet droppings and increased feed cost [1-3]. Nutritionists have termed this problem the "new season grain problem" [4].

Newly harvested grain should be stored for a period of several weeks or months to enhance its nutritional value [2]. During storage, respiratory and metabolic events continue, and changes in internal factors, such as starch, endogenous enzymes and carbonyl compounds in cell walls and external factors occur $[5,6]$. Among these factors, endogenous proteolytic enzymes play a central role in regulating the synthesis and decomposition of carbohydrates and proteins $[7,8]$.

Proteomics is an important tool that can be used to determine the biological roles and functions of individual proteins that govern grain seed quality and allow for the systematic analysis of complex cellular mechanisms [9]. Reports of corn proteome expression during the artificial aging period indicate that artificial aging would increase proteases and breakdown stored proteins, and impair metabolism and energy supplies $[10,11]$. However, the physicochemical properties of naturally aging corn have yet to be elucidated. Our objective was to delineate the proteomic mechanisms that underlie differences between corn stored for different time.

There is a clear link between bird performance and gut microbiota composition [12]. The intestinal microbiota plays an important role in maintaining normal gut function and contributes to the development of functional gastrointestinal symptoms by modulating the signaling pathways of hosts [13]. We have previously shown that using newly harvested corn leads to overfeeding and increased ileum lesions and injuries in broiler chickens [3]. Intestinal injury is associated with diarrhea and impaired gut resistance to pathogens [14]. Leonard et al. [15] reported that grain (rice, oats, barley and corn) protein is one of the most common triggers of enterocolitis syndrome. Additionally, non-digestible polysaccharides in corn can be broken down by members of the intestinal microbiota, producing monosaccharides and short-chain fatty acids (SCFAs), leading to unbalanced energy status [16]. Intestinal bacterial composition changes and their subsequent metabolic changes when a diet containing newly harvested corn is fed to broiler chickens and how they affect performance and health are unclear.

We herein first employed a combined high-throughput label-free comparative proteomics and metagenomics to study the biological mechanisms that underlie the relationship between the composition of natural aging corn and the diversity of the complex intestinal microbial community of broiler chickens.

\section{Materials And Methods}

\section{Plant material}

One newly harvested mixed corn variety corn (ZhengDan 958) was sourced from Hebei Province. The corn was sown in March 2015 and harvested in September 2015. After natural drying to 14\% moisture content, intact corn grains were stored from September to November in a warehouse located at the China Agricultural University Poultry Experimental Base without air conditioning to simulate typical grain 
storage conditions. The newly harvested corn was sampled after storage for half a month (HM) or two months (TM), frozen immediately in liquid nitrogen and stored at $-80^{\circ} \mathrm{C}$ until further analysis. At the same time, broilers fed the corn stored for different period of the time were used to further examine the differences between different storage times of corn. To eliminate the influence of the environment and animals, the same variety of corn stored for one year with the same moisture content was treated as the control in the broiler trial.

\section{Determination of pasting properties, total soluble sugar, glucose and fructose}

The corn samples were analyzed for pasting properties and soluble sugar. The pasting properties of corn mixtures stored for different times and suspended in distilled water were determined by a Rapid ViscoAnalyzer (model RVA-4C, Newport Scientific Pty. Ltd., Warriewood, Australia) and estimated by the method of Achayuthakan and Suphantharika [17]. Total soluble sugars were estimated by the phenolsulfuric acid method of Dubois et al. [18], using sucrose as the standard. Glucose and fructose were determined by the HPLC method of Wilson et al. [19].

\section{Label-free proteomic analysis process}

\section{Protein extraction and digestion}

The $\mathrm{HM}$ and $\mathrm{TM}$ samples were thawed $a{ }^{\circ}-80^{\circ} \mathrm{C}$ and then ground and hereafter, $100 \mathrm{mg}$ of each sample was weighed. Then $400 \mathrm{uL}$ SDT lysis buffer (4\% SDS, $100 \mathrm{mM}$ Tris-Hcl, $1 \mathrm{mM} \mathrm{DTT,} \mathrm{pH} \mathrm{7.6)} \mathrm{was} \mathrm{added} \mathrm{to}$ the sample, followed by solubilization for 20 s with a tissue homogenizer; this was repeated 5 times. After 20 min ultrasonic treatment, the mixture was centrifuged for 30 min at $10,000 \times \mathrm{g}$ at $4^{\circ} \mathrm{C}$, and the supernatant was saved for subsequent experiments. The BCA assay was used for protein quantification.

Protein digestion (200 $\mu \mathrm{L}$ for each sample) was performed using the FASP procedure described by Wisniewski [20]. Briefly, the detergent DTT, and other low molecular weight components were removed using $200 \mu \mathrm{L}$ UA buffer (8M Urea, $150 \mathrm{mmol} / \mathrm{L}$ Tris-HCl, $\mathrm{pH} 8.0)$ and facilitated by centrifugation $(14,000 \mathrm{~g}$ $\times 15 \mathrm{~min})$. Then, the $100 \mu \mathrm{L}$ IAA (50mmol/L IAA in UA) was added in UA buffer, and the mixture was oscillated for $1 \mathrm{~min}$ at $600 \mathrm{r} / \mathrm{min}$ and allowed to settle for $30 \mathrm{~min}$ in the dark at room temperature. The filter was washed with UA buffer $(100 \mu \mathrm{L})$ and $100 \mu \mathrm{L}$ of $\mathrm{NH}_{4} \mathrm{HCO}_{3}$ buffer twice. Subsequently, $40 \mu \mathrm{L}$ trypsin buffer $\left(4 \mu \mathrm{L}\right.$ Trypsin in $\left.40 \mu \mathrm{L} \mathrm{NH}_{4} \mathrm{HCO}_{3}\right)$ was added. The mixture was oscillated for $1 \mathrm{~min}$ at 600 $\mathrm{r} / \mathrm{min}$ and allowed to settle for $16-18 \mathrm{~h}$ at $37^{\circ} \mathrm{C}$, and the resulting peptides were collected. The filtrate was desalinized with C18 SD Extraction Disk Cartridge and quantified at OD280.

\section{LC-MS/MS Analysis}

Approximately $2 \mu \mathrm{L}$ product of protein digestion was used for LC-MS/MS analysis and separated using a nanoliter HPLC Ultimate 3000 system. The mobile phase A was $0.1 \%$ formic acid solution, and the mobile phase $B$ was $0.1 \%$ formic acid solution with $80 \%$ acetonitrile. The chromatographic column $\mathrm{C} 18$ trap column (C18 $3 \mu \mathrm{m} 0.10 \times 20 \mathrm{~mm})$ was balanced with $95 \%$ A solution. The sample was loaded onto the C18 


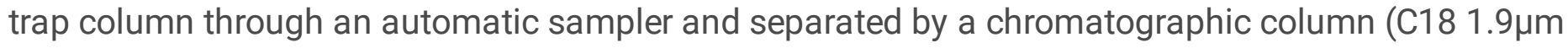
$0.15 \times 120 \mathrm{~mm}$ ) at the flow rate of $600 \mathrm{~nL} / \mathrm{min}$. The gradient elution procedure was as described in supplemental Table $\mathrm{S} 1$.

\section{Maxquant Label-Free Quantification analysis}

The 6 resulting raw LC-MS/MS files were imported to the MaxQuant software (1.3.0.5) and Proteome Discoverer 2.0 (thermo) for database inquiry and LFQ label-free quantification analysis. The database was corn_160605.fasta; enzyme:trypsin; max missed cleavage: 2; fixed modifications: carbamidomethyl (C); variable modifications: oxidation(M), acetyl (Protein N-term); peptide Mass Tolerance $₫ \pm 15 \mathrm{ppm}$; Fragment mass tolerance: $20 \mathrm{mmu}$; peptide confidence: high; peptide length:>4. The cutoff for the global false discovery rate (FDR) in peptide and protein identification was 0.01 . Label-free quantification was performed using MaxQuant as previously described [21]. Intensity-based absolute quantification (iBAQ) in MaxQuant was performed to quantify protein abundance for the identified peptides. An FDR estimation for differentially expressed proteins was performed using a mixture model-based method [22]. The significance of the differentially expressed proteins between the samples was examined with the cutoff values $P \leq 0.05$ and FDR $\leq 0.05$.

\section{Bioinformatics analysis}

Differentially expressed proteins (DEPs) were subjected to Core Expression Analysis. In this study, the DEPs between HM and TM was undertaken. The ratio values in the datasets were converted to fold change values, where the negative inverse was taken for values between 0 and 1 . The sequence data for the selected differentially expressed proteins were retrieved from the UniProtKB database in batches and FASTA format. Following the annotation and annotation augmentation steps, the studied proteins were blasted against KEGG GENES (plants) to retrieve the KOs and were subsequently mapped to pathways in KEGG.

\section{Animals and experimental design}

The experiment was assigned to two periods following the corn storage time. During each period, seventy-two 7 -day old male broiler chickens (Ross 308) were obtained from a commercial hatchery and grown for 14 days. Birds were randomly assigned to one of two dietary treatments (HM vs control or TM vs control). There were 6 replicates per treatment and 6 birds per replicate. Feed (pelleted) and water were provided ad libitum. The light regimen was $23 \mathrm{~L}: 1 \mathrm{D}$ and the room temperature was $28-30^{\circ} \mathrm{C}$. All the corn samples used to formulate basal broiler diets that met broiler recommendations of NY/T33-2004 (Table S2).

\section{Sample collection and DNA extraction}

The experimental layout is shown in Fig 1. At 14 days of age, a metabolic experiment was conducted, and 3 randomly selected chickens (remaining birds were still fed with basal diets) per cage were moved to the new cages and fed with either HM, TM or control metabolic diets (Table S3) for 3 days. Total excreta 
outputs and feed intakes were recorded from 15 to 18-days post hatching. Excreta were dried in a forcedair oven at $60^{\circ} \mathrm{C}$ for 48 hours and the gross energy of excreta and metabolic diets were determined using an adiabatic bomb calorimeter to determine apparent metabolizable energy (AME) and nitrogen-corrected $\operatorname{AME}\left(\mathrm{AME}_{\mathrm{n}}\right)$.

At 21-days post-hatching, the 3 remaining birds in each cage were euthanized by injection with $5 \%$ pentobarbital sodium. Immediately following euthanasia, the abdominal cavity was opened and the duodenal contents, approximately $3 \mathrm{~cm}$ lengths of duodenum were removed for gut morphological measurements. For viscosity measurements, jejunal digesta were collected and diluted with (1:1) distilled water and homogenized for $20 \mathrm{~min}$ at room temperature before centrifugation. The viscosity was measured according to the method of Piel et al. [23].

The cecum was collected within 5 min of euthanasia, immediately placed in cryogenic vials, snap-frozen in liquid nitrogen and stored at $-80^{\circ} \mathrm{C}$ until DNA extraction. Total genomic DNA was isolated from $220 \mathrm{mg}$ of frozen cecal contents using the QIAmp DNA Stoll Kit. The DNA concentration and purity were determined using a NanoDrop 2000 spectrophotometer (Thermo Scientific). Three samples per treatment were selected for further analysis.

\section{Morphological examination}

Intestinal samples were immersed in formaldehyde, before being fixed in Bouin's solution and embedded in paraffin. The length of the intestinal villi and the depth of the intestinal crypt were measured with a linear scaled graticule. The number of goblet cells and lymphocytes $/ \mu \mathrm{m}^{2}$ area of the villus and crypts was measured by 25 squared graticules.

\section{Metagenome analysis process}

\section{DNA library construction and sequencing}

DNA libraries were generated using NEBNext ${ }^{\circledR}$ Ultra TM DNA Library Prep Kit for Illumina (NEB, USA) following manufacturer's recommendations. Briefly, the DNA sample was fragmented by sonication to a size of 350bp, then end-polished, A-tailed, and ligated with the full-length adaptor for Illumina sequencing. PCR products were purified (AMPure XP system) and libraries were analysed for size distribution by Agilent2100 Bioanalyzer and quantified using real-time PCR. The clustering of the index-coded samples was performed on a cBot Cluster Generation System. Then, the library preparations were sequenced on an Illumina HiSeq platform and paired-end reads were generated.

\section{Gene catalogue construction}

We performed de novo assembly and gene prediction for the high quality reads of 6 samples in stage I using SOAP denovo v1.06 [24] and GeneMark v2.7 [25], respectively. All predicted genes were aligned pairwise using BLAT and genes, of which over $90 \%$ of their length can be aligned to another one with more than $95 \%$ identity (no gaps allowed), were removed as redundancies, resulting in a non-redundant 
gene catalogue comprising of 659,733 genes. This gene catalogue from our cecal samples was further combined with the previously constructed CD-HIT gene catalogue [26], by removing redundancies in the same manner. At last, we obtained an updated gene catalogue that contains 362,337 genes.

\section{Taxonomic assignment of genes}

Taxonomic assignment of the predicted genes was performed using DIAMOND [27]. In our analysis, we collected the reference microbial genomes from Non-Redundant (NR) of NCBI (v 2014-10-19), and then aligned all genes onto the reference genomes. For each gene, the highest scoring hit(s) above these two thresholds was chosen for the genus assignment. For the taxonomic assignment at the phylum level, the $65 \%$ identity was used instead.

\section{Functional annotation}

The functional annotation and abundance analysis of KEGG (Kyoto Encyclopedia of Genes and Genomes), and carbohydrate enzyme (CAZy) (version: 2014.11.25) were performed using BLASTP (evalue $\leq 1 \mathrm{e}-5$ ). Based on the species abundance and functional abundance, the abundance cluster analysis, and sample cluster analysis were performed.

\section{Statistical Analysis}

LEfSe analysis uses the Kruskal-Wallis rank sum test to detect significantly different abundances and performs LDA scores to estimate the effect size (threshold:>2). Statistical analyses were performed using SPSS software, version 16.0 (SPSS Inc., Chicago, IL, USA). The data were subjected to an analysis of variance (ANOVA), the means were compared using Student's t-tests, and the differences were considered significant at $P \leq 0.05$.

\section{Results}

\section{Corn properties}

The pasting characteristics of corn stored at different times determined by the RVA are summarized in Table 1. Storage time resulted in significant $(P \leq 0.05)$ decreases in peak viscosity, final viscosity, and setback viscosity and an increase in pasting temperature. At the same time, a significant change in soluble sugars was observed during storage of corn for the two periods (Fig 2A.). Lower total concentrations $(P \leq 0.05)$ of glucose and fructose were found in corn stored for two months (Fig 2B.).

\section{Proteome variation of corn in response to different storage times}

By merging all identified protein lists including those from two time points and three biological replicates, 2499 proteins were identified and 1984 proteins were quantified from all samples. For further analysis, the $\mathrm{TM} / \mathrm{HM}$ ratios were log2 transformed. Relative quantifications of 1984 proteins were divided into two categories: proteins with quantitative ratios over 1.5 and $P \leq 0.05$ were considered upregulated, while 
proteins with quantitative ratios $\leq 1 / 1.5(0.67)$ and $P \leq 0.05$ were considered downregulated. Venn diagram analysis showed that 222 proteins were influenced by storage time, among these proteins (Fig S1).

\section{Differentially expressed proteins in corn stored for different times}

We identified a total of 26 proteins that were differentially expressed, among which only 2 diminished proportionally to HM corn, while 24 proteins seemed to be positively influenced by the increase in storage time (Table 2). Peptidyl-prolylcis-transisomerase and jasmonate-induced protein were downregulated in TM compared with HM. The other identified proteins were upregulated in TM compared with HM. Among these proteins, GRMZM2G162359_P01, GRMZM2G008216_P02 and GRMZM5G825695_P01 proteins have no known functions and no annotations could be found to assign or predict their functions.

\section{Functional annotation of identified proteins}

GO terms were assigned to the 222 differentially expressed proteins. Fig 3 . shows $\mathrm{GO}$ annotations for proteins that were differentially expressed in HM and TM. The identified proteins cover a wide range of cellular processes, molecular functions and cellular components and can be classified into 22,8 , and 7 categories in these broad groups, respectively. The differentially expressed proteins in the biological functions category were mainly associated with cellular ketone metabolic, carboxylic acid metabolic and cellular amino acid biosynthetic processes. The largest group within the molecular function category was cofactor binding. The cellular component functions mainly belong to the cytoplasm and mitochondrion. KEGG results showed for the most differentially expressed proteins suggest that these proteins are involved in 13 pathways (Fig S2).

\section{Bird properties affected by corn storage}

The relative AME and AMEn values of each batch are shown in Fig 4. Both AME and AMEn were significantly higher $(P \leq 0.05)$ in $\mathrm{HM}$ than in TM.

With increased corn storage, the relative digesta viscosity decreased significantly ( $P \leq 0.05)$ (Fig $5 A)$. The total number of goblet cells and lymphocytes was lower in chickens fed the TM diet (Fig 5B). There were no significant differences between treatments in crypt and villi (Fig S3).

\section{Taxonomic characterization of the gut microbiota}

A total of 1,870,386 ORFs were predicted. Among these ORFs, $82.06 \%, 78.41 \%, 71.55 \%, 69.39 \%, 53.90 \%$, $49.20 \%$ and $41.02 \%$ had annotations at the kingdom, phylum, class, order, family, genus and species levels, respectively. Unclassified ORFs accounted for $17.94 \%$ of unigenes, representing novel rhizosphere taxa. The abundance was compared between groups, number of significantly changed genes are showed in a Venn diagram. When compared to HM corn treatment, a total of 97141 genes were significantly changed in the TM groups, and 110678 genes were changed in the HM groups (Fig S4). 
We aligned the reads to a catalog, and the majority of aligned reads were bacterial and dominated by the phyla Firmicutes, Bacteroidetes, and Proteobacteria followed by Actinobacteria, Tenericutes, Fusobacteria and Spirochaetes. Bacteroidetes, Proteobacteria and Tenericutes were significantly enriched in stored corn subjects, while the relative abundance of Fusobacteria was significantly increased in newly harvested corn ( $P \leq 0.05)$ (Fig 6A.). Clostridium, Eubacterium, Bacteroides and Blatutia were the most abundant genera in our treatments. Compared with the newly harvested corn, stored corn significantly increased 8 kinds of genera bacterium such as Allstipes, Butyricicoccus and Mycoplasma (Fig 6B.). Species and genome level abundances were also calculated to determine the composition of the gut microbiota (Fig S5.), we compared the composition HM and TM communities and observed increases in Faecalibacterium prausnitzii, Barnesiella intestinihominis, Bacteroides dorei and Firmicutes bacterium CAG:475 in TM compared with HM. There were decreases in the abundance of Bacteroides fragilis, Subdoligranulum variabile, Ruminococcus torques, Eubacterium sp. ER2, Clostridium sp. CAG:678 and Ruminococcaceae bacterium D16 in TM compared with HM.

\section{AME and AMEn are correlated with microbiota}

The global RDA model that selected AME and AMEn as the meaningful explanatory variables was significant $(P \leq 0.05)$ (Fig 7.). The overall variation in species composition was attributed to these explanatory variables, of which the majority were explained by the first and second axes variation, which accounted for 47.1 and $7.4 \%$, respectively. In Fig 5B, we highlight 7 species that were significantly correlated with one or both of the first two RDA axes. Among these, Acidaminococcus.sp.CAG.917 was strongly associated with AME while Alistipes.sp..CAG.157, Bacteroides.dorei, Bacteroides. uniformis and Oscillibacter.ruminantium were correlated with AMEn.

\section{LefSe analysis}

The LefSe test detected differences in the relative abundances of bacterial taxa across samples (Fig 8). Among the genes from the species level, Alistipes and Firmicutes bacterium, Bacillus, Mycoplasma, Alistipes inops, Barnesiella intestinihominis, Barnesiella and Ruminococcus were significantly enriched in the TM treatment, while Eubacterium desmoians, Hungatella hathewayi, Hungatella, Lachnociostridum, Bacteroides fragilis, Fusobacterium and Eubacterium were significantly enriched in the HM treatment $($ LDA $>2, P<0.05)$.

\section{Functional analysis and bacterial metabolic processes}

The function of bacterial assemblages associated with different storage times of corn was cataloged using level 3 KEGG orthologs. Several KEGG level 2 modules were different between the two treatments. HM treatment significantly improved the metabolism of terpenoids and polyketides and amino acid metabolism, while TM had beneficially influenced metabolism of other amino acids, folding, sorting and degradation, glycan biosynthesis and metabolism and transport and catabolism and immune system ( $P \leq 0.05$, Fig 9). At KEGG level 3, compared with HM treatment, TM was enriched for carbohydrate metabolism (e.g., amino sugar and nucleotide sugar metabolism and pyruvate metabolism) (Fig 10A), 
glycan biosynthesis and metabolism (e.g., glycan degradation) (Fig 10B) and the immune system (e.g., RIG-I-like receptor signaling pathway) (Fig 10C). Interestingly, we also found a different pathway for bacterial invasion of epithelial cells which could putatively increase the expression of SipD and SipB in the Salmonella infections pathway, and increased the IpaB expression in the Shigella infections pathway in HM (Fig 11A.B). The CAZymes analysis showed that longer corn storage times resulted in higher levels of the following subsystems when compared with the shorter storage treatments; cellulose_synthase, chitin_oligosaccharide synthase, chitin_synthase, xylanase, arabinanase and glucosaminidase (Table S4).

\section{Discussion}

\section{The effect of storage on corn properties}

Compared to freshly harvested grain, a change in protein digestibility was reported by Paraginski et al. [5] and Ramchandran et al. [28], potentially due to protein and starch solubility. One of the most sensitive indices of the aging in grain is the change in pasting properties $[29,30]$ which is related to the granule size and soluble materials of starch [31]. As storage duration increased, peak viscosity, final viscosity and setback decreased which were in agreement with previous studies [32,33]. This is attributed to the formation of a complex between amylose and lipids and thereby restriction of granular swelling.

Dietary sugars (glucose and fructose) that escape absorption in the mammalian intestine and reach the microbiota disrupt colonization by beneficial microbes [34]. In the current study we observed an increase in total soluble sugars and reductions in glucose and fructose in the stored corn which were in concordance with the findings of Paraginski [5]. We observed that higher oligosaccharide and lower monosaccharide contents in stored corn could benefit gut health [35].

\section{Differentially expressed proteins}

We studied the effect of corn storage and carbohydrate composition as storage is known to exhibit strong effects on starch biosynthesis [36]. Li et al. [37] reported that starch retrogradation is mainly caused by the aggregation of amylose and occurs during the early stage of storage. 1,4-a-glucanbranching enzyme activity catalyzes ADP-glucose into amylopectin, inhibiting starch retrogradation [37,38]. The upregulation of the 1,4-a-glucan-branching enzyme in TM suggested a decrease in the amount of amylose and an increase in amylopectin which could increase the waterinsolubility of starch and protein [39]. During storage, respiratory and metabolic events continue. Pyruvate, phosphate dikinase and phosphoenolpyruvate carboxylase family proteins play key roles in $\mathrm{CO}_{2}$ transport and fixation, respectively [40]. Higher activities of these two enzymes under TM suggested a higher synthetic ratio of starch when carbon gain exceeds the carbon demands for growth (accumulation) [41].

In addition to storage, the upregulation of cellulose synthase, a catalytic subunit could catalyze secondary cell wall biogenesis and improve the ability to defend against bacteria and fungi. The 
significant upregulation of dirigent proteins, which are thought to play important roles in plant secondary metabolism and are the first intermediates for lignan biosynthesis, was observed in stored corn [42]. Lignans are known to form building blocks for the formation of lignin in the plant cell wall and are metabolized by intestinal bacteria and exhibit strong antioxidant and bioactive properties such as enzymes and protein synthesis, cell proliferation, growth factor action and cell differentiation [43].

The aging process affects storage proteins, proteins related to cell growth and division, and cell defense [44]. During storage, grain seeds could mobilize the storage substances in a timely and efficient manner to obtain a sufficient carbon source and energy supply for germination. The upregulation of Legumin-1 in stored corn suggested that germination activity could be improved with storage. Protein oxidation (carbonylation) and reduced translation always occur during aging [45].

\section{Functional annotation of identified proteins}

In the current study, the molecular function of most proteins was related to the activity of peptidase. Peptidases are enzymes that hydrolyze peptide bonds in proteins and peptides and release amino acids, peptides, and proteins from larger peptides and proteins [46]. From the cellular process analysis, storage duration had a major impact on protein homeostasis and induced proteins involved in metabolic processes (mainly the protein catabolic process and amino acid biosynthetic process). For dried stored corn seed, free amino acids in grain increased with storage and there is a decrease in the lower molecular weight peptides and an increase in the higher molecular weight peptides [39]. The texture changes in stored grains are the consequence of modifications by of carbohydrate polymers by component polysaccharides via hydrolytic enzyme activity. The chemical and proteomic analysis results suggest that storage probably induced an increase in large molecular weight starch and protein and produced modifications in solubility. This could lead to lower starch pasting properties and higher concentrations of beneficial oligosaccharides which could affect animal health.

\section{Whole genome shotgun metagenome analysis}

In the current study, increased storage time resulted in increased AME and AMEn, is similar to the results reported by Fuente et al. [47]. The intestinal flora has been recently proposed to affect body weight and energy homeostasis. The results from our RDA analysis showed a strong correlation between AME and Acidaminococcus sp. which has an effect on growth through the fermentation of glutamate [48]. Mucin is secreted by goblet cells along the villi of the epithelium. The present study has indicated that the number of goblet cells was decreased under the TM corn treatment. Goblet cell function reveled the metabolic and inflammatory phenotypes to the intestinal microbiota. Johansson et al. [49] reported that more antinutritional factors led to epithelial cell apoptosis along the villi and crypts, fusion of villi and more and larger goblet cells. On the other hand, the regeneration of epithelial goblet cells is consistent with Acidaminococcus colonization [50].

The lower enrichment of Firmicutes under the TM treatment was in concordance with the result of Stanley et al. [51] who reported that a class of Firmicutes was negatively correlated with poultry energy 
utilization. Members of the genus Bifidobacteria are the main gut microbiota recognized as being beneficial for health. Two months stored corn significantly upregulated the enrichment of Bifidobacteria which impacts positively the host and the target of prebiotic functional foods and supplements [52]. At the genus level, we found that TM treatment had lower enrichment in eggerthella. Eggerthella have been implicated as a cause of ulcerative colitis, liver and anal abscesses and systemic bacteremia [53].

Bacteroides fragilis, a gram-negative, obligately anaerobic bacterium that was negatively correlated with AMEn was found in the present study to reduce the host immune response toward pathogenic bacteria by suppressing inflammatory pathways ${ }^{[54]}$. Enterotoxin production by $B$. fragilis was identified and subsequently found to produce severe diarrheal disease in several intact animals [55]. Strauss et al. [56] reported that Fusobacterium isolated from IBD patients is a bacterial species associated with inflammatory disease. From the Lefse analysis, newly harvested corn treatment led to higher relative abundance of Hungatella hathewayi, Bacteroides fragilis and Fusobacterium which might colonize the gut and produce enterotoxins to induce the diarrheal response and be the major reason for the "newly harvested grain problem". Hungatella hathewayi can cause a wide spectrum of illnesses ranging from mild diarrhea to pseudomembranous colitis [57]. The TM treatment seemed to enrich in butyrateproducing bacteria such as Alistipes that typically play anti-inflammatory roles. Thus, prolonging the storage time could improve gut health by decreasing the abundance of harmful microorganisms in the intestine.

\section{Microbial gene functional diversity}

The core functions of the intestinal microorganisms include pathways associated with carbohydrate and amino acid fermentation. It has been demonstrated that the cecal microbiome was enriched in genes involved in carbohydrate metabolism plus the metabolism of galactose and fructose from the stored corn. Several dietary components, especially polysaccharides such as inulin, fructooligosaccharides or xylan are not modified or absorbed in the intestine and are considered as prebiotic promoting the growth of beneficial bacteria [58]. These microbes essentially assist the host in deriving maximum nutritional value from the components of the diet. Microbial fermentation of indigestible polysaccharides results in the production of SCFAs which are linked to the immune system and enterocyte development [59].

Glycoside hydrolases (GHs) are essential enzymes required for the breakdown of polysaccharides. Polysaccharide degrading enzymes contribute to metabolic energy. The higher activities of GHs found in TM were associated with the better utilization of energy such as AME and AMEn and related to the production of SCFAs. The distal gut microbiome provides the host with the capacity to degrade these glycans. In addition, many members of the microbiota possess the ability to synthesize new polysaccharides de novo. Bacterial production of capsular polysaccharides is associated with increased resistance to phages, complements, and antimicrobial peptides [54]. Bacteroides spp. are known to breakdown a wide variety of otherwise indigestible dietary plant polysaccharides (eg., amylose, amylopectin and pullulan) [60], while proteomic analysis showed that higher amylopectin synthetase activity with the storage of corn might contribute to increasing the abundance of Bacteroides under the 
TM and stimulate glycan biosynthesis and metabolism. Glycosphingolipids are building blocks of the plasma membrane that determine lipid rafts and are involved in cell functions such as proliferation, apoptosis and embryogenesis [61]. Higher enrichment in glycosphingolipids for TM suggests that stored corn fed to broilers could improve the function of epithelial cells.

Beyond digestion and metabolism, the microbiota contributes to the development and maintenance of the intestinal epithelial barrier, development of the immune system, and competition with pathogenic microorganisms. Among these systems, RIG-Ilike receptor signaling plays a major role in pathogen sensing of RNA viral infection to initiate and modulate antiviral immunity [62], and it was influenced by the treatments. Salmonella infections have the capacity to modulate cellular functions and induce profuse actin cytoskeleton rearrangements and nuclear responses that ultimately lead to bacterial uptake and the production of proinflammatory cytokines [63]. Shigellae are the etiological agents of bacillary dysentery and the acute form of diarrhea accompanied by blood and mucus [64]. Newly harvested corn increases the expression of SipD and SipB in the Salmonella infection pathway and increases IpaB expression in the Shigella infections pathway. SipB and IpaB apparently bind and activate caspase-1 and result in the stimulation of an unconventional form of programmed cell death with features of necrosis, which was in accordance with the intestinal morphological results. Consequently, a higher possibility of Salmonella and Shigellae infections could potentially occur in broiler chickens fed a diet made from newly harvested corn, which could result in diarrhea and intestinal epithelial cell death.

\section{Conclusion}

Natural aging of newly harvested corn is a complex process. We used proteomics to identify 26 proteins that could be responsible for the synthesis of large molecules and change the solubility of starch and protein, as well as soluble sugars and decrease pasting properties. Compared with newly harvested corn, two-month-stored corn appears to have a decreased abundance of harmful bacteria such as Hungatella hathewayi and Bacteroides fragilis, with an enrichment of butyrate-producing bacteria such as Alistipes in the guts of broiler chickens. The functional roles of these host bacteria coupled with the low risk of diarrhea and higher utilization of energy are clues to the underlying mechanisms of the "new grain problem".

\section{Abbreviations}

HM: Half months stored corn; TM: Two months stored corn; AME: Apparent Metabolisable Energy; $\mathrm{AME}_{\mathrm{n}}$ : nitrogen-corrected Apparent Metabolisable Energy; SCFA: Short-Chain Fatty Acids; DEPs: Differentially Expressed Proteins; IBD: Inflammatory Bowel Disease; RVA: Rapid Visco-Analyzer; CAZy: carbohydrate enzyme; GHs: Glycoside hydrolases; HPLC: High Performance Liquid Chromatography; LDA: Linear Discriminant Analysis; RDA: Redundancy analysis

\section{Declarations}




\section{Availability of data and material}

The datasets used and /or analyzed during the current study are available from the corresponding author on request.

\section{Acknowledgements}

This research was supported by National Natural Science Foundation of China (No. 31772620), and the System for Poultry Production Technology, Beijing Agriculture Innovation (BAIC 04-2021).

\section{Funding}

This research was supported by National Natural Science Foundation of China (No. 31772620), and the System for Poultry Production Technology, Beijing Agriculture Innovation (BAIC 04-2021).

\section{Conflict of interest}

The authors declare no conflicting interests.

\section{Author contributions}

YD and YJ designed the study. WY, WL and BX performed all calculations. YD, WY and SEA performed all assays. YD wrote the first draft. All authors revised the text.

\section{Ethics declarations}

All procedures complied with the Beijing Regulations for Laboratory Animals, and the study was approved by The Laboratory Animal Ethical Committee of China Agricultural University (study approval reference number AW60701202-2-1). All methods were carried out in accordance with relevant guidelines and regulations (supplemental material "ethics approval").

\section{References}

1. Zhong G, Shen Y, Zhang S, Wang Q, Song Z et al. Effects of newly harvested corn on growth performance, intestine development and metabolism of nutrients in broilers. Ita J Anim Sci. 2019; 18(1):505-512.

2. Tang D, Du B, Yan R, Chen Z, Nian F. Effect of dietary-aged maize on growth performance, nutrient utilization, and serum metabolites in broilers. Anim Biotechnol. 2021; 1-16.

3. Yin D, Yin X, Wang $X$, Lei Z, Wang $M$ et al. Supplementation of amylase combined with glucoamylase or protease changes intestinal microbiota diversity and benefits for broilers fed a diet of newly harvested corn. J Anim Sci Biotechnol. 2018; 9: 24-37. 
4. Choct M, Hughes RJ. The nutritive value of new season grains for poultry. Recent Advances in Animal Nutrition in Australia. 1997

5. Paraginski RT, Vanier NL, Berrios JD, de Oliveira M, Elias MC. Physicochemical and pasting properties of maize as affected by storage temperature. J Stored Prod Res. 2014; 59: 209-214.

6. Shi JY, Wu MD, Quan MM. Effects of protein oxidation on gelatinization characteristics during rice storage. J Cereal Sci. 2017; 75: 228-233.

7. Lv Y, Tian P, Zhang S, Wang J, Hu Y. Dynamic proteomic changes in soft wheat seeds during accelerated ageing. Peer J. 2018; 6e5874.

8. Han Z, Bin W, Zhang J, Guo S, Zhang H et al. Mapping of QTLs associated with seed vigor to artificial aging using two RIL populations in maize (Zea mays L.). Agr Sci. 2018; 9(4): 397-415.

9. Yan H, Mao P. Comparative time-course physiological responses and proteomic analysis of melatonin priming on promoting germination in aged oat (Avena sativa L.) seeds. Int J Mol Sci. 2021; 22(2): 811.

10. Wu XL, Liu HY, Wang W, Chen SN, Hu XL et al. Proteomic analysis of seed viability in maize. Acta Physiol Plant. 2011; 33(1): 181-191.

11. Xin X, Lin XH, Zhou YC, Chen XL, Liu X et al. Proteome analysis of maize seeds: the effect of artificial ageing. Physiol Plantarum. 2011;143(2): 126-138.

12. Iqbal Y, Cottrell JJ, Suleria HA, Dunshea FR. Gut microbiota-polyphenol interactions in chicken: a review. Animals. 2020; 10(8): 1391.

13. Choi KY, Lee TK, Sul WJ. Metagenomic analysis of chicken gut microbiota for improving metabolism and health of chickens - a review. Asian Austral J Anim. 2015; 28(9): 1217-1225.

14. Zhang WD, Zhu B, Xu JH, Liu YY, Qiu EQ et al. Bacteroides fragilis protects against antibioticassociated diarrhea in rats by modulating intestinal defenses. Front Immunol. 2018; 9: 1040-1055.

15. Leonard SA, Pecora V, Fiocchi AG, Nowak-Wegrzyn A. Food protein-induced enterocolitis syndrome: a review of the new guidelines. World Allergy Organ. 2018; 1: 14-13.

16. Shortt C, Hasselwander O, Meynier A, Nauta A, Fernandez EN et al. Systematic review of the effects of the intestinal microbiota on selected nutrients and non-nutrients. Eur J Nutr. 2018; 57(1): 25-49.

17. Achayuthakan $P$, Suphantharika M. Pasting and rheological properties of waxy corn starch as affected by guar gum and xanthan gum. Carbohyd Polym. 2008; 71(1): 9-17.

18. Dubois M, Gilles KA, Hamilton JK, Rebers PA, Smith F. Colorimetric method for determination of sugars and related substances. Anal Chem. 1956; 28(3): 350-356. 
19. Wilson AM, Work TM, Bushway AA, Bushway RJ. Hplc Determination of fructose, glucose, and sucrose in potatoes. J Food Sci. 1981; 46(1): 300-301.

20. Wisniewski JR, Zougman A, Nagaraj N, Mann M. Universal sample preparation method for proteome analysis. Nat Methods. 2009; 6(5): 359-U360.

21. Schwanhausser B, Busse D, Li N, Dittmar G, Schuchhardt J et al. Global quantification of mammalian gene expression control. Nature. 2013; 495(7439): 126-127.

22. Efron B. Size, power and false discovery rates. Ann Stat. 2007; 35(4): 1351-1377.

23. Piel $C$, Montagne L, Sève B, Lallès J-P. Increasing digesta viscosity using carboxymethylcellulose in weaned piglets stimulates ileal goblet cell numbers and maturation. J Nutr. 2005; 135(1): 86-91.

24. Luo RB, Liu BH, Xie YL, Li ZY, Huang WH et al. SOAPdenovo2: an empirically improved memoryefficient short-read de novo assembler. Gigascience. 2012; 1:18-24.

25. Mende DR, Waller AS, Sunagawa S, Jarvelin Al, Chan MM et al. Assessment of metagenomic assembly using simulated next generation sequencing data. Plos One. 2012; 7(2): 31386-31397.

26. Fu LM, Niu BF, Zhu ZW, Wu ST, Li WZ. CD-HIT: accelerated for clustering the next-generation sequencing data. Bioinformatics. 2012; 28(23): 3150-3152.

27. Buchfink B, Xie C, Huson DH. Fast and sensitive protein alignment using DIAMOND. Nat Methods. 2015; 12(1): 59-60.

28. Ramchandran D, Hojilla-Evangelista MP, Moose SP, Rausch KD, Tumbleson ME et al. Changes in corn protein content during storage and their relationship with dry grind ethanol production. J Am Oil Chem Soc. 2018; 95(8): 923-932.

29. Perdon AA, Siebenmorgen TJ, Buescher RW, Gbur EE. Starch retrogradation and texture of cooked milled rice during storage. J Food Sci. 1999; 64(5): 828-832.

30. Zhu B, Zhan J, Chen L, Tian Y. Amylose crystal seeds: Preparation and their effect on starch retrogradation. Food Hydrocolloid. 2020; 105: 105805.

31. Keawpeng I, Venkatachalam K. Effect of aging on changes in rice physical qualities. Int Food Res J. $2015 ; 22(6): 2180-2187$.

32. Sowbhagya CM, Bhattacharya KR. Changes in pasting behaviour of rice during ageing. J Cereal Sci. 2001; 34(2): 115-124.

33. Tulyathan V, Leeharatanaluk B. Changes in quality of rice (Oryza sativa L.) cv. Khao Dawk Mali 105 during storage. J Food Biochem. 2007; 31(3): 415-425. 
34. Townsend GE, Han WW, Schwalm ND, Raghavan V, Barry NA et al. Dietary sugar silences a colonization factor in a mammalian gut symbiont. P Natl Acad Sci USA. 2019; 116(1): 233-238.

35. Ibrahim 00. Functional oligo-saccharides: chemicals structure, manufacturing, health benefits, applications and regulations. J Food Chem Nanotechnol. 2018; 4: 65-76.

36. Niu L, Ding H, Zhang J, Wang W. Proteomic analysis of starch biosynthesis in maize seeds. StarchStärke. 2019; 71(9-10): 1800294.

37. Li W, Li C, Gu Z, Qiu Y, Cheng L et al. Retrogradation behavior of corn starch treated with 1,4-alphaglucan branching enzyme. Food Chem. 2016; 203: 308-313.

38. Fan LJ, Bao JD, Wang Y, Yao JQ, Gui YJ et al. Post-domestication selection in the maize starch pathway. Plos One. 2009; 4(10): 7612-7621.

39. Saikrishna A, Dutta S, Subramanian V, Moses JA, Anandharamakrishnan C. Ageing of rice: A review. J Cereal Sci. 2018; 81: 161-170.

40. González-Segura L, Mújica-Jiménez C, Juárez-Díaz JA, Güémez-Toro R, Martinez-Castilla LP et al. Identification of the allosteric site for neutral amino acids in the maize C4 isozyme of phosphoenolpyruvate carboxylase: The critical role of Ser-100. J Biol Chem. 2018; 293(26): 9945-9957.

41. Chapin FS, Schulze ED, Mooney HA. The Ecology and Economics of Storage in Plants. Annu Rev Ecol Syst. 1990; 21423-447.

42. Pickel B, Schaller A. Dirigent proteins: molecular characteristics and potential biotechnological applications. Appl Microbiol Biot. 2013; 97(19): 8427-8438.

43. Puupponen-Pimia R, Aura AM, Oksman-Caldentey KM, Myllarinen P, Saarela M et al. Development of functional ingredients for gut health. Trends Food Sci Tech. 2002; 13(1): 3-11.

44. Zhang YX, Xu HH, Liu SJ, Li N, Wang WQ et al. Proteomic analysis reveals different involvement of embryo and endosperm proteins during aging of Yliangyou 2 hybrid rice seeds. Front Plant Sci. 2016; 71: 394-1411.

45. Rajjou L, Lovigny Y, Groot SPC, Belghaz M, Job C et al. Proteome-wide characterization of seed aging in Arabidopsis: A comparison between artificial and natural aging protocols. Plant Physiol. 2008; 148(1): 620-641.

46. Rawlings ND, Barrett AJ, Bateman A. Asparagine Peptide Lyases a seventh catalytic type of proteolytic enzymes. J Biol Chem. 2011; 286(44): 38321-38328.

47. Fuente JM, De Ayala PP, Flores A, Villamide MJ. Effect of storage time and dietary enzyme on the metabolizable energy and digesta viscosity of barley-based diets for poultry. Poult Sci. 1998; 77(1): 90- 
97.

48. Gough EK, Stephens DA, Moodie EEM, Prendergast AJ, Stoltzfus RJ et al. Linear growth faltering in infants is associated with Acidaminococcus sp and community-level changes in the gut microbiota. Microbiome. 2015; 3: 24-34.

49. Johansson ME, Hansson GC. Is the intestinal goblet cell a major immune cell? Cell host microbe. 2014; 15(3): 251-252.

50. Westrin KM, Stierna P, Carlsöö B, Nord CE. Mucosubstance histochemistry of the maxillary sinus mucosa in experimental sinusitis: a model study on rabbits. ORL. 1991; 53(5): 299-304.

51. Stanley D, Geier MS, Denman SE, Haring VR, Crowley TM et al. Identification of chicken intestinal microbiota correlated with the efficiency of energy extraction from feed. Vet Microbiol. 2013; 164(1-2): 8592.

52. Jacobs DM, Gaudier E, van Duynhoven J, Vaughan EE. Non-digestible food ingredients, colonic microbiota and the impact on gut health and immunity: a role for metabolomics. Curr Drug Metab. 2009; 10(1): 41-54.

53. Lau SKP, Woo PCY, Woo GKS, Fung AMY, Wong MKM et al. Eggerthella hongkongensis sp nov and Eggerthella sinensis sp nov., two novel Eggerthella species, account for half of the cases of Eggerthella bacteremia. Diagn Micr Infec Dis. 2004; 49(4): 255-263.

54. Martens EC, Roth R, Heuser JE, Gordon Jl. Coordinate Regulation of Glycan Degradation and Polysaccharide Capsule Biosynthesis by a Prominent Human Gut Symbiont. J Biol Chem. 2009; 284(27): 18445-18457.

55. Sack RB, Myers LL, Almeidohill J, Shoop DS, Bradbury WC et al. Enterotoxigenic Bacteroides fragilis: epidemiologic studies of its role as a human diarrhoeal pathogen. J Diarrhoeal Dis Res. 1992; 10(1): 4-9.

56. Strauss J, Kaplan GG, Beck PL, Rioux K, Panaccione R et al. Invasive potential of gut mucosa-derived fusobacterium nucleatum positively correlates with IBD status of the host. Inflamm Bowel Dis. $2011 ; 17(9):$ 1971-1978.

57. Manzoor SE, McNulty CAM, Nakiboneka-Ssenabulya D, Lecky DM, Hardy KJ et al. Investigation of community carriage rates of Clostridium difficile and Hungatella hathewayi in healthy volunteers from four regions of England. J Hosp Infect. 2017; 97(2): 153-155.

58. Thomson P, Medina DA, Ortuzar V, Gotteland M, Garrido D. Anti-inflammatory effect of microbial consortia during the utilization of dietary polysaccharides. Food Res Int. 2018; 109: 14-23.

59. Ibrahim M, Anishetty S. A meta-metabolome network of carbohydrate metabolism: Interactions between gut microbiota and host. Biochem Bioph Res Co. 2012; 428(2): 278-284. 
60. Xu J, Bjursell MK, Himrod J, Deng S, Carmichael LK et al. A genomic view of the human-Bacteroides thetaiotaomicron symbiosis. Science. 2003; 299(5615): 2074-2076.

61. Tettamanti G, Bassi R, Viani P, Riboni L. Salvage pathways in glycosphingolipid metabolism. Biochimie. 2003; 85(3-4): 423-437.

62. Loo YM, Gale M. Immune Signaling by RIG-I-like Receptors. Immunity. 2011; 34(5): 680-692.

63. Hernandez LD, Pypaert M, Flavell RA, Galan JE. A Salmonella protein causes macrophage cell death by inducing autophagy. J Cell Biol. 2003; 163(5): 1123-1131.

64. Hilbi H, Moss JE, Hersh D, Chen YJ, Arondel J et al. Shigella-induced apoptosis is dependent on Caspase-1 which binds to IpaB. J Biol Chem. 1998; 273(49): 32895-32900.

\section{Tables}

Table 1. Pasting properties of different storage time cornstrong>

\begin{tabular}{llllll} 
Sample & $\begin{array}{l}\text { Peak viscosity } \\
(\mathrm{RVA})\end{array}$ & $\begin{array}{l}\text { Breakdown } \\
(\mathrm{RVA})\end{array}$ & $\begin{array}{l}\text { Final viscosity } \\
(\mathrm{RVA})\end{array}$ & $\begin{array}{l}\text { Setback } \\
(\mathrm{RVA})\end{array}$ & $\begin{array}{l}\text { Pasting } \\
\text { temperature }\left({ }^{\circ} \mathrm{C}\right)\end{array}$ \\
\hline $\mathrm{HM}$ & $1796 \pm 42.2$ & $166 \pm 21.4$ & $3087 \pm 123.0$ & $1457 \pm 71.6$ & $77.6 \pm 0.13$ \\
\hline $\mathrm{TM}$ & $1602 \pm 68.6$ & $99 \pm 32.9$ & $2711 \pm 34.5$ & $1208 \pm 10.6$ & $78.1 \pm 0.13$ \\
\hline -value & 0.014 & 0.162 & 0.007 & 0.004 & 0.036 \\
\hline
\end{tabular}

Mean \pm standard deviation.

HM, half months stored corn; TM, two months stored corn. 
Table 2. Proteins identified as differentially expressed from Label-free LC-MS/MS

\begin{tabular}{|c|c|c|c|c|}
\hline Accession number & Protein Description & $\begin{array}{l}\mathrm{TM} / \mathrm{HM} \\
\text { Ratio }\end{array}$ & $\begin{array}{l}\mathrm{P}- \\
\text { value }\end{array}$ & KO \\
\hline GRMZM5G866758_P02 & Acetyl-CoA acetyltransferase, cytosolic & 1.75 & 0.002 & \\
\hline GRMZM2G174883_P01 & Legumin 1 & 1.67 & 0.012 & K03671 \\
\hline GRMZM2G055434_P01 & Early nodulin & 1.94 & 0.013 & \\
\hline GRMZM2G023347_P01 & Prefoldin subunit & 1.50 & 0.015 & \\
\hline GRMZM2G010762_P01 & Early nodulin-like protein & 1.54 & 0.018 & K00700 \\
\hline GRMZM2G020423_P01 & Jasmonate-induced protein & 0.61 & 0.019 & K00626 \\
\hline GRMZM2G016958_P01 & IAA-amino acid hydrolase & 2.07 & 0.019 & K01507 \\
\hline GRMZM2G041881_P01 & $\begin{array}{l}\text { Nascent polypeptide-associated complex } \\
\text { subunit beta }\end{array}$ & 4.27 & 0.020 & \\
\hline GRMZM2G059353_P01 & $\begin{array}{l}\text { Non-green plastid inner envelope } \\
\text { membrane protein }\end{array}$ & 1.81 & 0.021 & \\
\hline GRMZM2G162359_P01 & Uncharacterized protein & 1.97 & 0.021 & K13448 \\
\hline GRMZM2G473463_P01 & $\begin{array}{l}\text { Mitochondrial import inner membrane } \\
\text { translocase subunit }\end{array}$ & 1.57 & 0.026 & \\
\hline GRMZM2G105712_P05 & 605 acidic ribosomal protein & 1.81 & 0.029 & K07304 \\
\hline GRMZM2G397044_P02 & Peptidyl-prolyl cis-trans isomerase & 0.34 & 0.031 & \\
\hline GRMZM2G163406_P01 & Dirigent protein & 2.45 & 0.033 & \\
\hline GRMZM2G032628_P01 & 1,4-alpha-glucan-branching enzyme 2 & 1.95 & 0.034 & K03232 \\
\hline GRMZM2G097457_P01 & Pyruvate, phosphate dikinase & 1.56 & 0.036 & \\
\hline GRMZM2G164714_P02 & $\begin{array}{l}\text { Phosphoenolpyruvate carboxylase } \\
\text { family protein }\end{array}$ & 1.57 & 0.037 & \\
\hline GRMZM2G071433_P01 & Plasma membrane associated protein & 1.60 & 0.038 & K03016 \\
\hline GRMZM2G008216_P02 & Uncharacterized protein & 1.67 & 0.040 & \\
\hline GRMZM2G445905_P03 & Cellulose synthase & 1.62 & 0.045 & \\
\hline GRMZM5G825695_P01 & Uncharacterized protein & 1.85 & 0.045 & K10999 \\
\hline GRMZM2G439201_P02 & Elongation factor 1-beta 2 & 2.09 & 0.045 & \\
\hline GRMZM2G026470_P01 & Soluble inorganic pyrophosphatase 1 & 1.54 & 0.046 & K01006 \\
\hline GRMZM2G306345_P01 & Pyruvate orthophosphate dikinase 1 & 1.61 & 0.047 & \\
\hline GRMZM2G085260_P01 & Desiccation-related protein & 1.68 & 0.049 & K02943 \\
\hline
\end{tabular}


HM, half months stored corn; TM, two months stored corn.

\section{Figures}

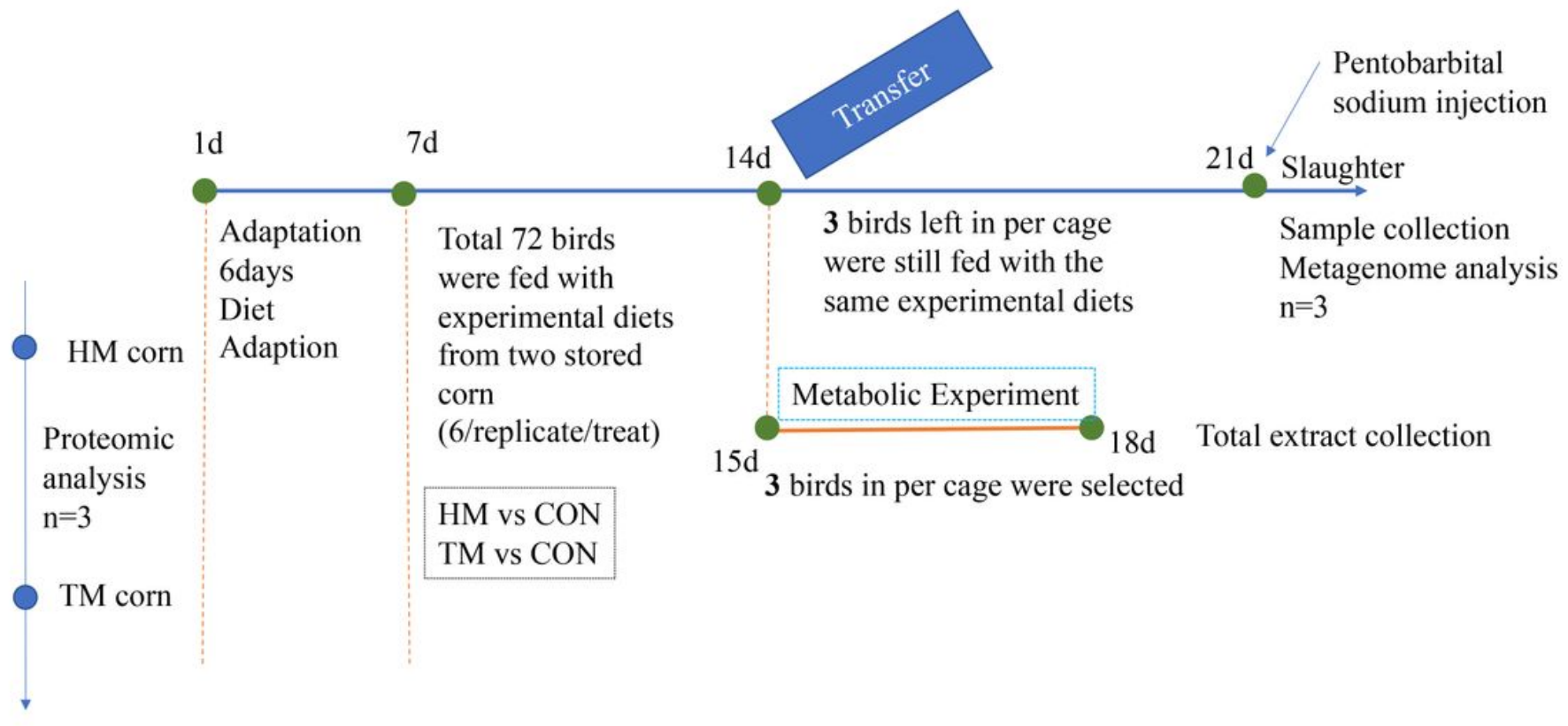

\section{Figure 1}

Experimental layout. Seventy two birds were divided into 2 groups, namely, HM and TM. On day 14, half birds in per treatment were selected to do metabolic experiment for three days. The left parts were still fed with experimental diets. On day 21, non-metabolic birds were killed to get samples for metagenome analysis $(n=3)$. 


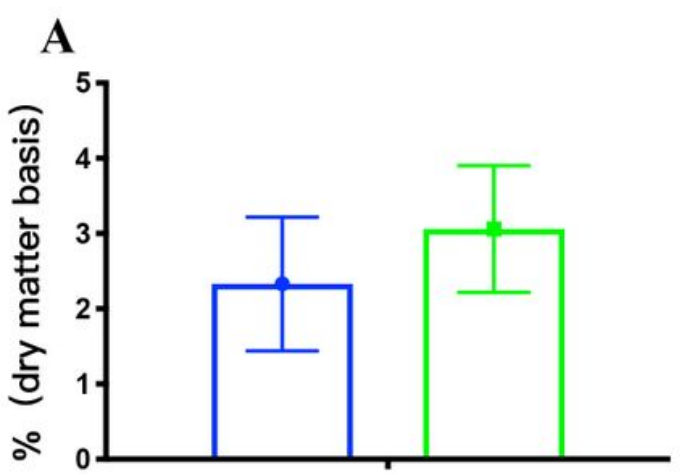

Total soluble sugars

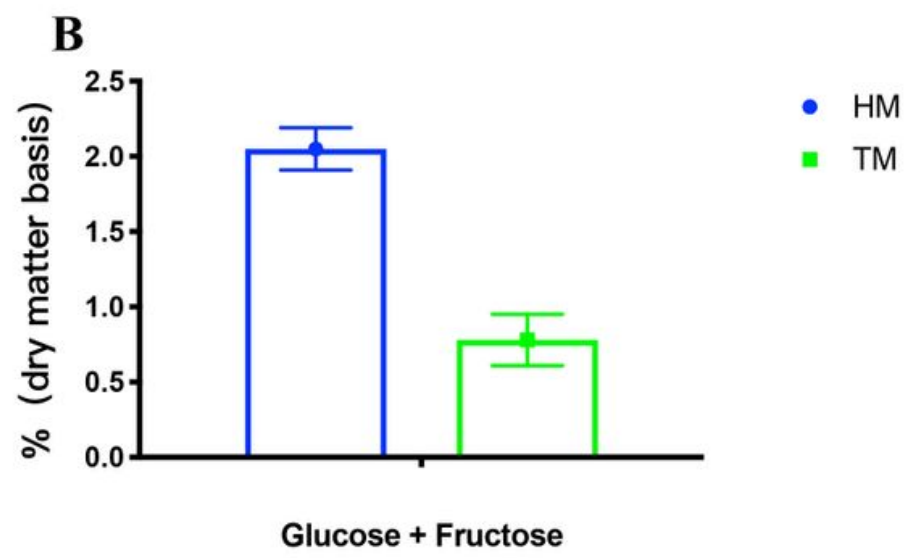

Figure 2

Storage effects on total soluble sugars (A) and total concentrations of glucose and fructose (B) of corn (mean \pm SD, triplicate samples). (HM, half month stored corn; TM, two months stored corn.) 


\section{Biological Process}

A

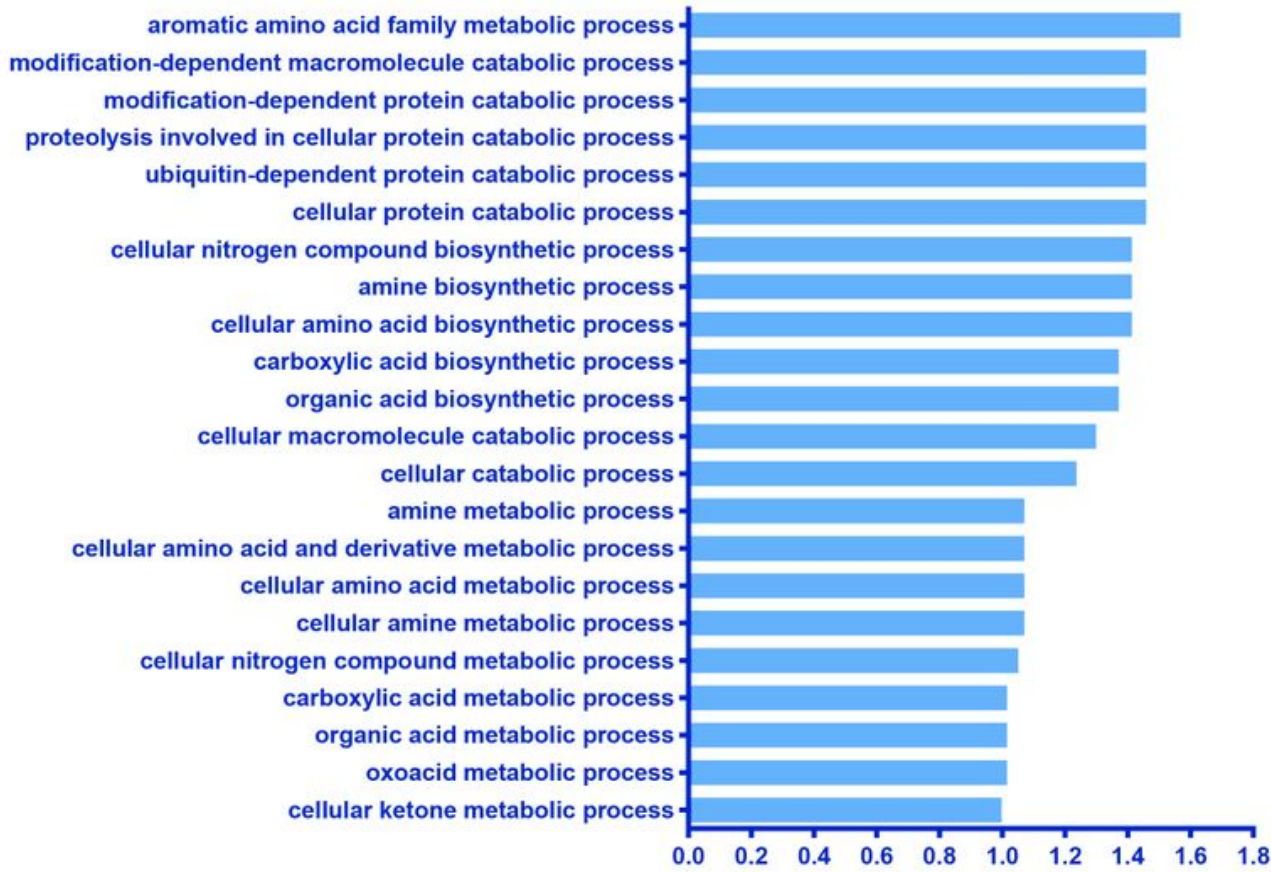

Molecular Function
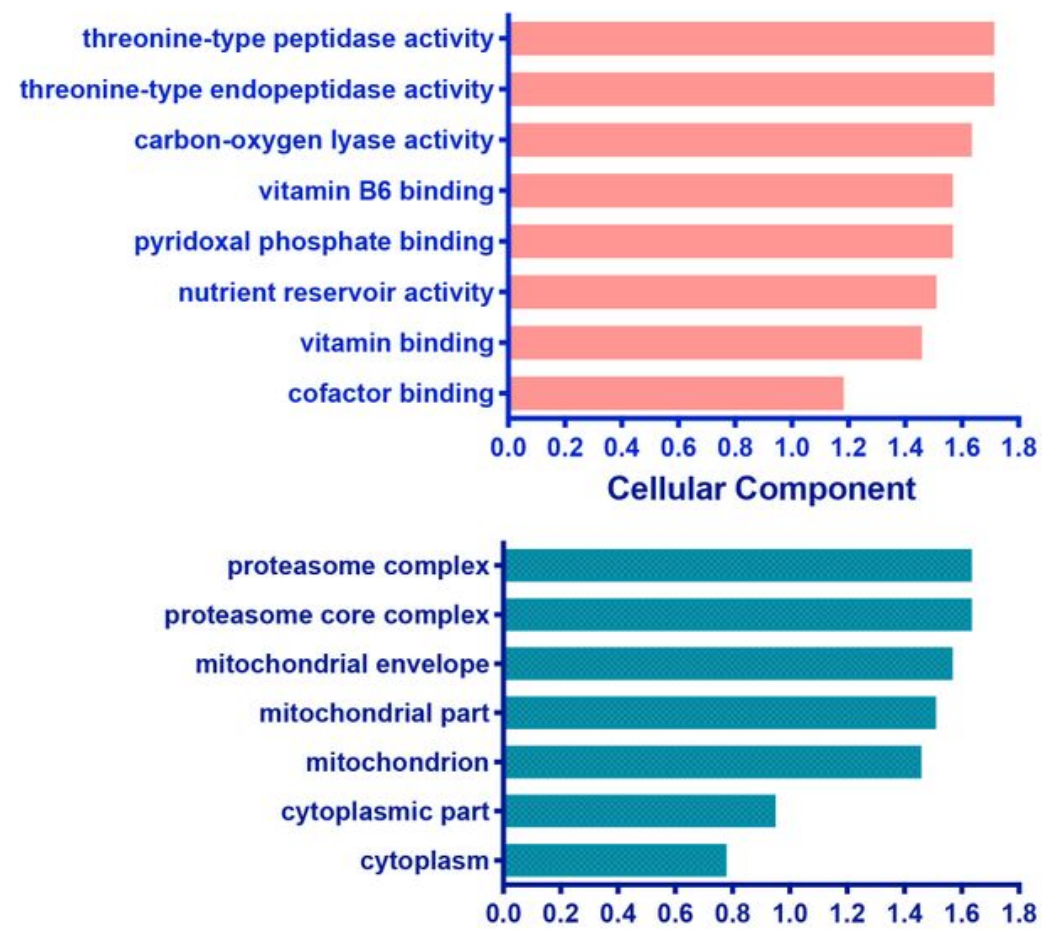

Figure 3

The proportion of the differentially expressed proteins categorized by function. A: Gene Ontology analysis for biological processes; B: Gene Ontology analysis for molecular function; C: Gene Ontology analysis for molecular function. 

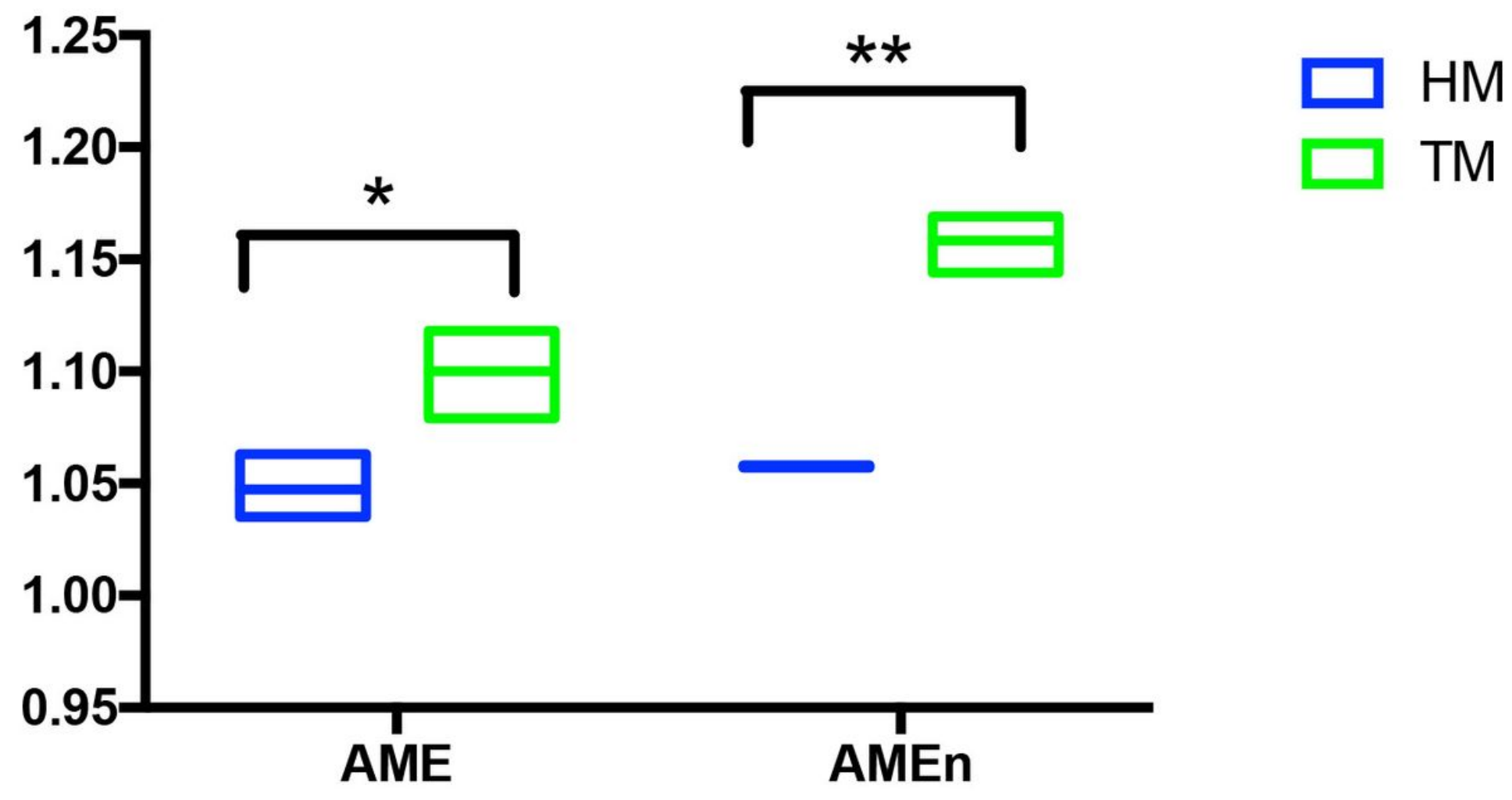

$\square$ TM

Figure 4

Storage effects on relative AME and AMEn to control groups of $17 d$ broiler chickens $(n=6)$. (* $P \leq 0.05$, ** $\mathrm{P} \leq$ 0.01. HM, half month stored corn; TM, two months stored corn.)

A

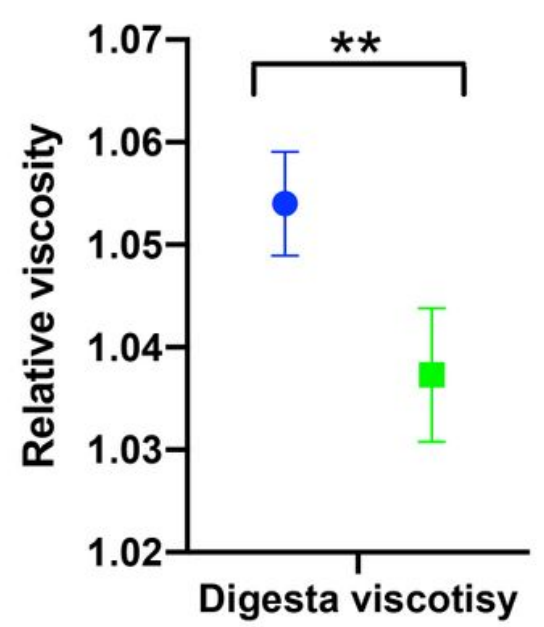

B

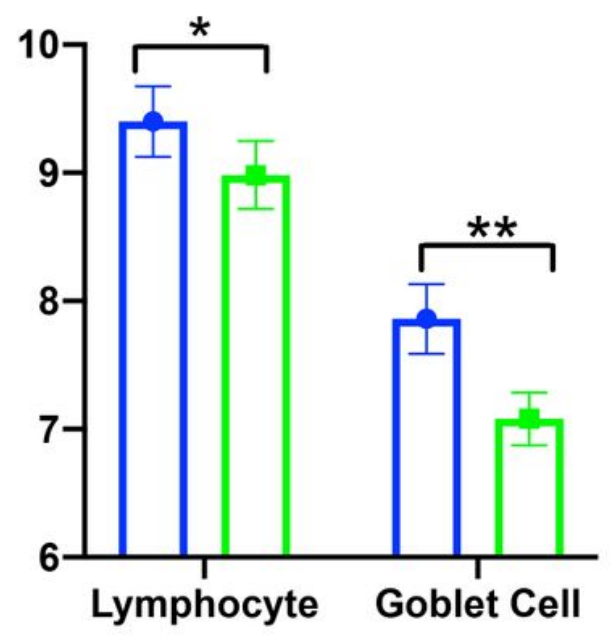

Figure 5 
Storage effects on relative digesta viscosity $(A)$ and lymphocytes and goblet cells number in duodenum $(n=6)$. (* $P \leq 0.05, * * P \leq 0.01$. HM, half month stored corn; TM, two months stored corn.)

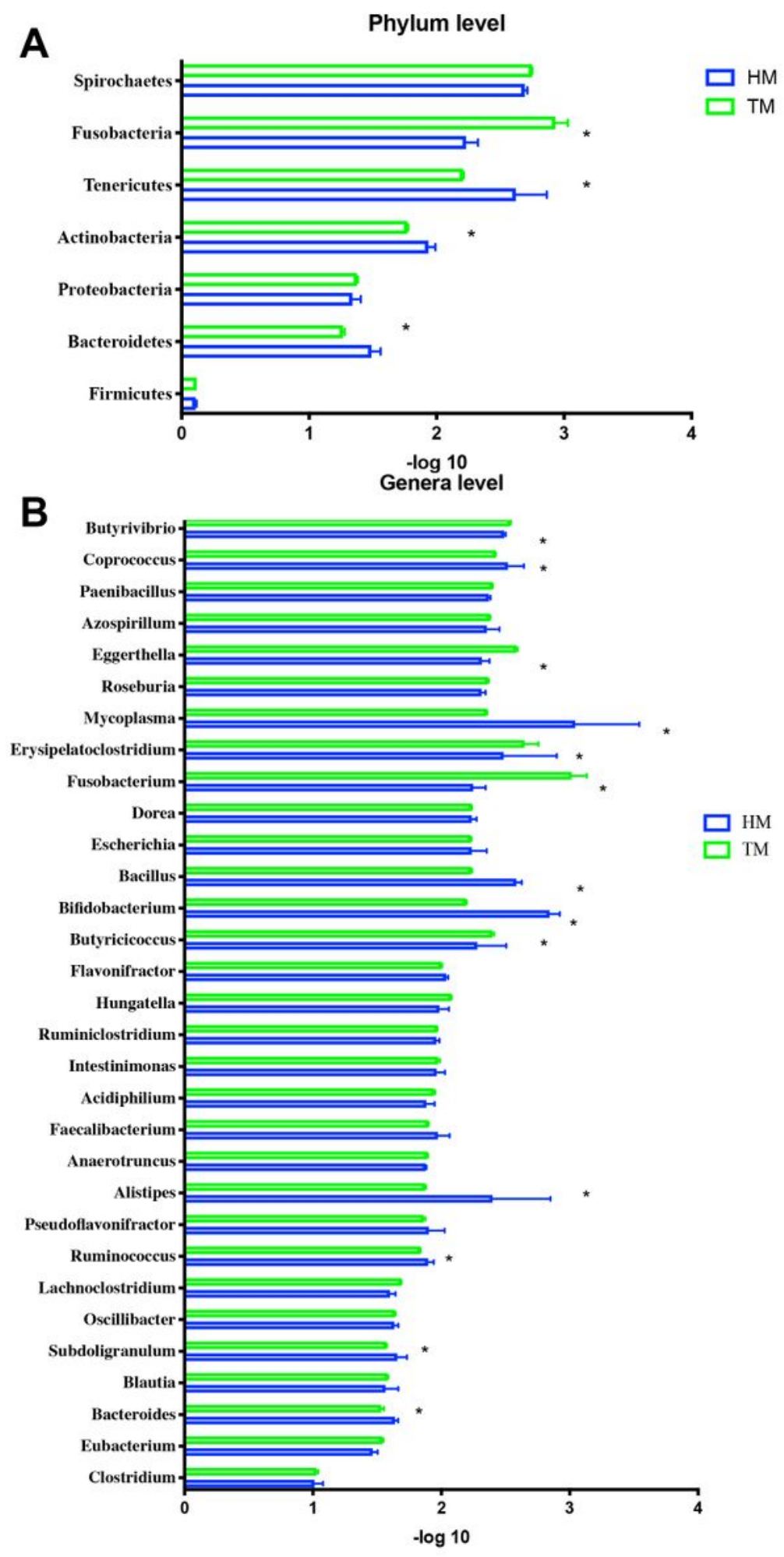

Figure 6

Relative abundance of annotated phylum (A) and significant different genus (B) in cecal microbiota of broilers. (HM, half month stored corn; TM, two months stored corn) * $P \leq 0.05$ 

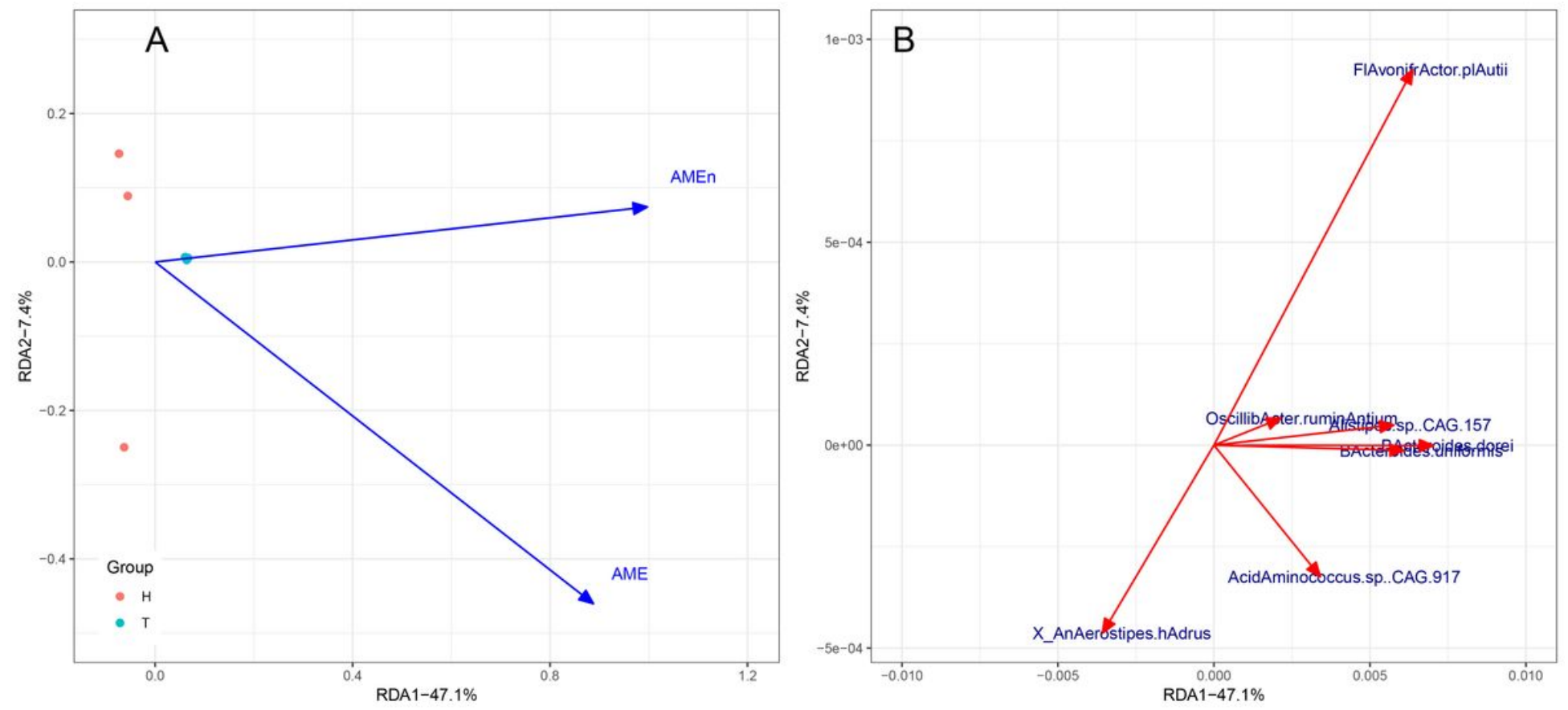

Figure 7

Bacterial abundance RDA correlation biplots by selected explanatory variables. The sites and explanatory variables (A) and species (B) plots are presented separately for clarity; they are divided from the same RDA model. H: half moths storage corn; $\mathrm{T}$ : two months storage corn. 


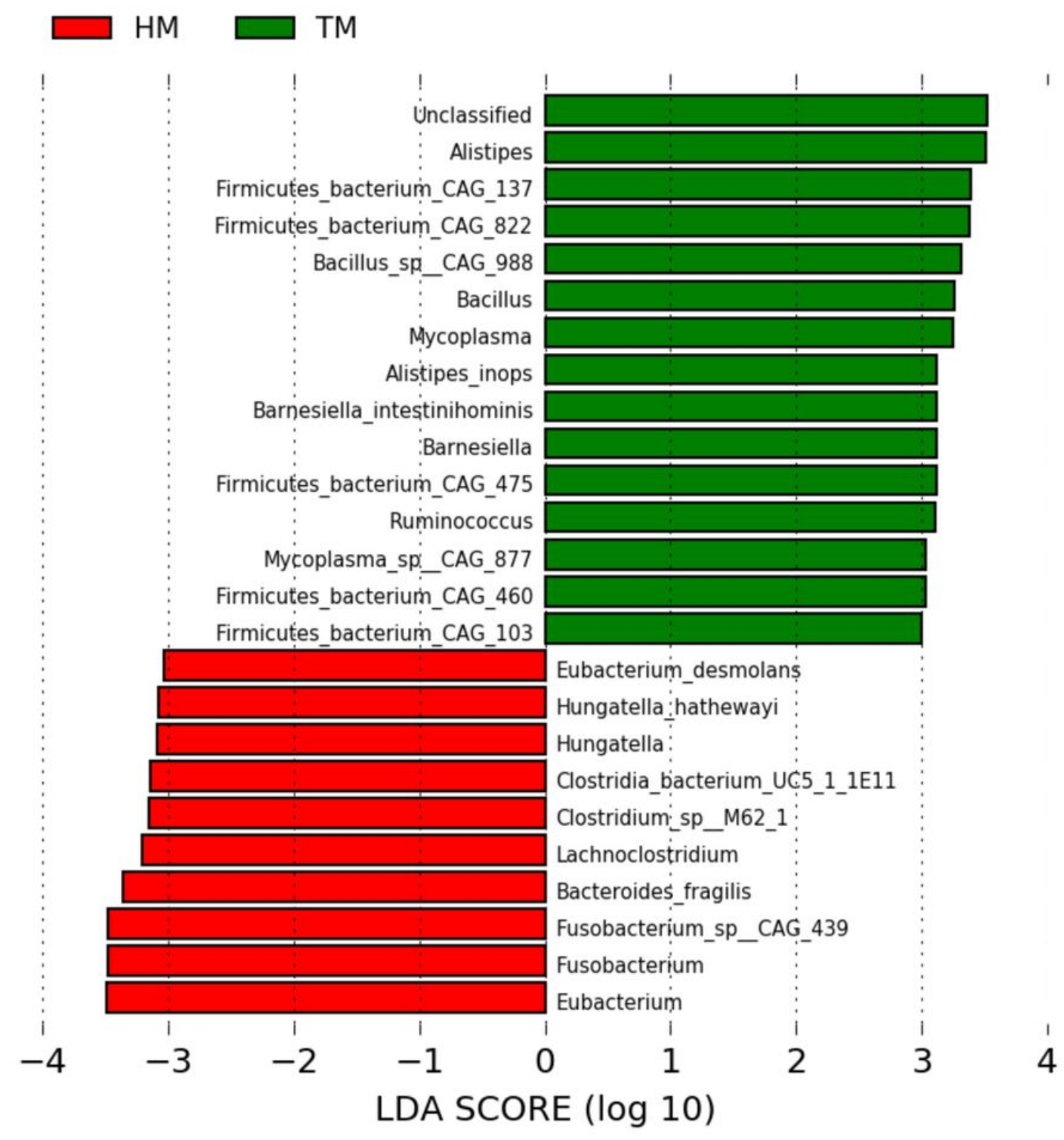

\section{Figure 8}

Species differentially represented between $\mathrm{HM}$ and TM samples identified by linear discriminant analysis coupled with effect size (LEfSe) (LDA >2, P<0.05). (HM (green), half month stored corn; TM (red), two months stored corn). 


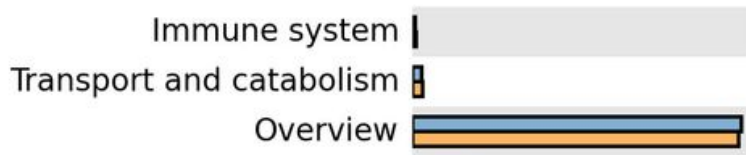

Glycan biosynthesis and metabolism

Environmental adaptation \&

Metabolism of other amino acids $\rightleftarrows$

" Folding, sorting and degradation"

Amino acid metabolism Metabolism of terpenoids and polyketides

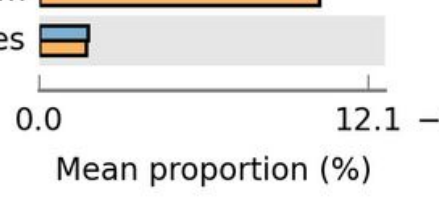

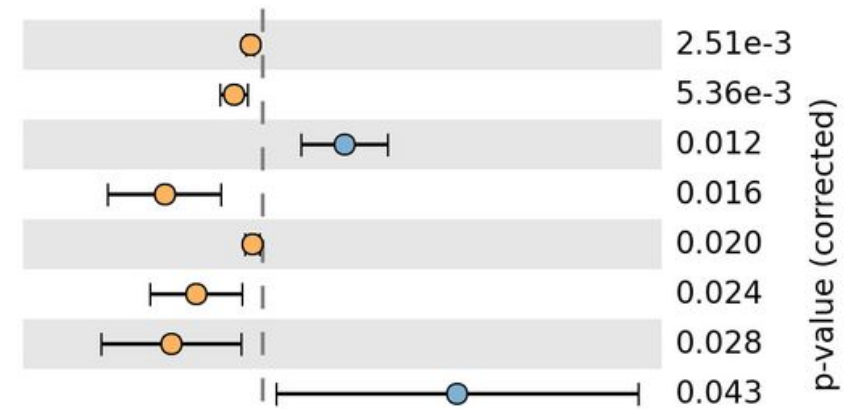

\section{Figure 9}

The significant different functions of the cecal microbiota of the broilers. Statistics of the number of annotated genes at KEGG metabolic pathway level two. (HM, half month stored corn; TM, two months stored corn).

A

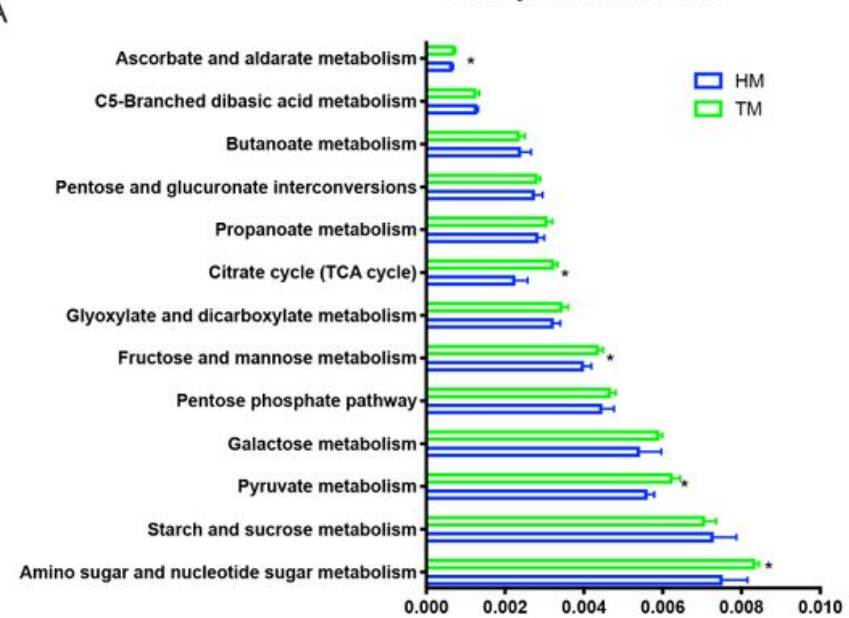

B

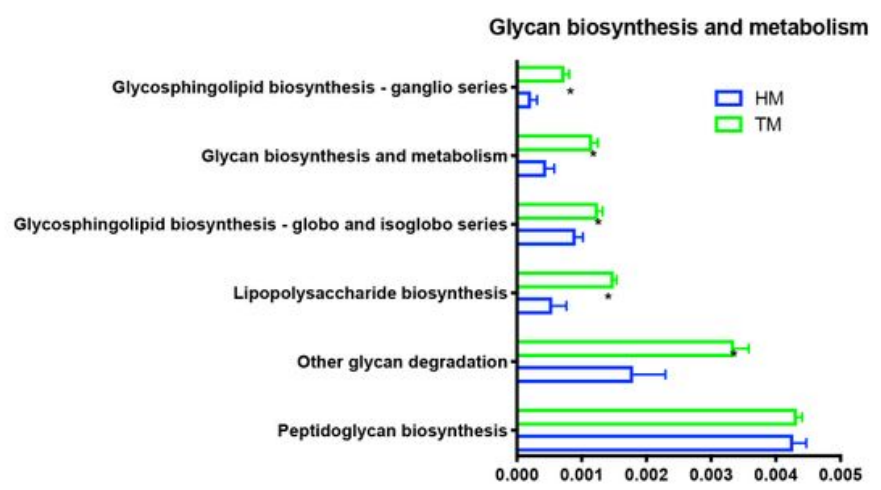

C

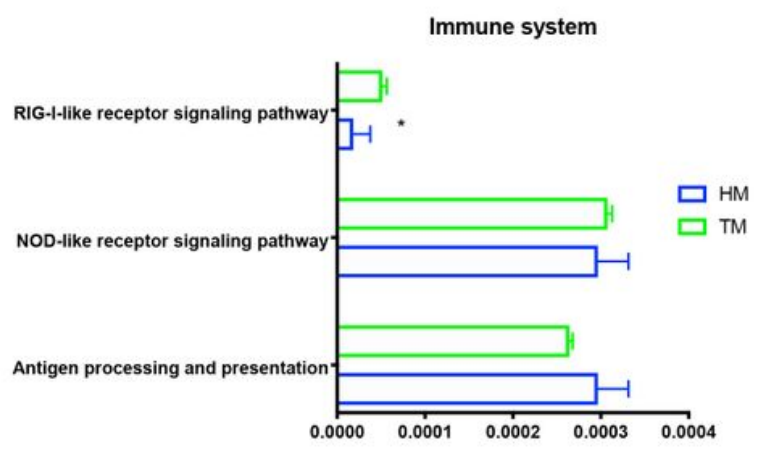

Figure 10 
Comparison of gene pathways of the cecal microbiota of broilers annotated genes at KEGG pathways at level three of carbohydrate metabolism (A), glycan biosynthesis and metabolism (B) and immune system (C). (HM, half month stored corn; TM, two months stored corn). * $\mathrm{P} \leq 0.05$

A

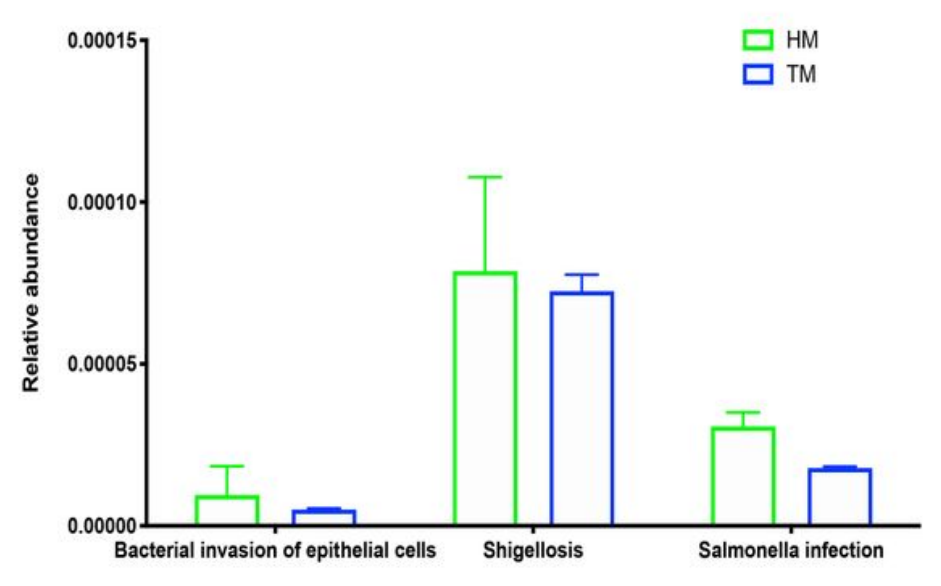

B

$$
\text { Salmonella infection Shigella infection }
$$

SipD SipC SipB IpaC IpaB

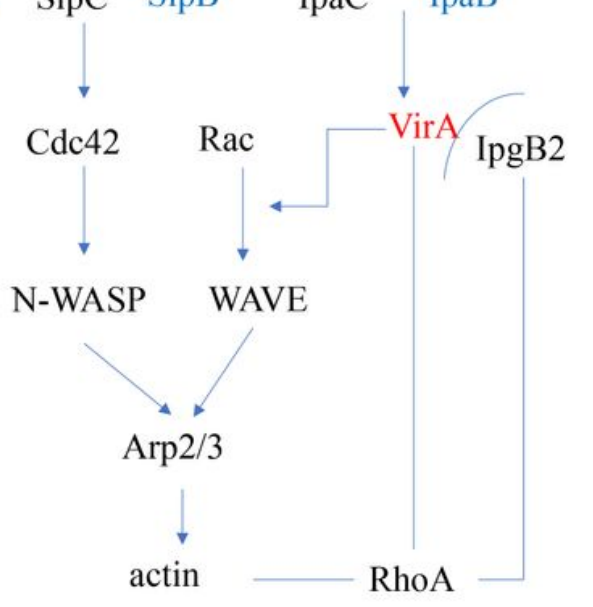

\section{Figure 11}

Comparison of pathogenic invasion related pathways of the cecal microbiota of broilers annotated genes at KEGG pathways at level three. (HM, half month stored corn; TM, two months stored corn).

\section{Supplementary Files}

This is a list of supplementary files associated with this preprint. Click to download.

- FigS1.docx

- renamedb908f.pdf 